\title{
An exploratory study of the impact of group singing activities on lucidity, energy, focus, mood and relaxation for persons with dementia and their caregivers
}

\author{
Jane W Davidson ${ }^{1 *}$ and Renita A Almeida ${ }^{2}$
}

\footnotetext{
* Correspondence:

j.davidson@unimelb.edu.au

${ }^{1}$ Faculty of the Victoria College of the Arts and the Melbourne Conservatorium of Music, The University of Melbourne, Building 141, Royal Parade, Parkville VIC 3010, Australia

Full list of author information is available at the end of the article
}

\begin{abstract}
Background: It is known that persons with dementia (PWD) suffer a variety of difficulties, with increased agitation as well as lowered mood, focus and lucidity being amongst their greatest challenges. Caregivers are also affected and report increased stress levels, as well as lower energy, mood and focus. The aim of the current study was to explore whether engagement in a singing program could result in improvement in these variables for both PWD and Caregivers.
\end{abstract}

Methods: Stage 1 investigated the impact of a structured singing session, with a verbal quiz functioning as a control activity. Participants were from both community and residential care contexts, the PWD having a diagnosis of mild or moderate dementia, and no significant differences in age between them and their caregivers. Stage 2 explored the effects of musical engagement over a six-week intervention with community-based participants.

Results: After the one-off singing session, quantitative positive changes in all PWD (both groups) were found on all four PWD variables from pre- to post-singing session. Further, caregivers' energy levels, mood, and focus were improved from pre- to post-singing session. Note that the quiz control group showed no such benefit. The six weeks of group singing demonstrated that the more regular attendance at the singing group sessions affected the PWD's baseline level of lucidity, mood, and focus, and on the caregivers' baseline relaxation level improved. Though participants were few, reflecting the real world circumstance of the organisations supporting the singing groups, increases in the baseline levels of the variables were detected from session to session, suggesting positive effect. Qualitative data offered supportive insights into the positive experience and powerful impact on PWD and the carers.

Conclusions: This exploratory work indicates the positive potential of using group singing to improve lucidity, mood, focus and to relax for PWD and their carers. Finding a cheap and easy route to improving quality of life for those affected by dementia is essential, and from this preliminary data it seems that singing may offer such a course.

Keywords: Music and dementia; Caregiver; Lucidity; Mood; Focus; Relaxation; Singing

\section{Springer}

(c) 2014 Davidson and Almeida; licensee Springer. This is an Open Access article distributed under the terms of the Creative Commons Attribution License (http://creativecommons.org/licenses/by/4.0), which permits unrestricted use, distribution, and reproduction in any medium, provided the original work is properly credited. 


\section{Introduction}

Dementia is a prevalent condition that profoundly affects quality of life. The Alzheimer's Disease International (ADI, World Alzheimer Report 2010) estimates that currently there are 35.6 million people worldwide who are suffering from dementia, with figures likely to increase to 65.7 million by 2030 and 115.4 million people by 2050. Given the urgent need to find tools for enhancing the quality of life for persons living with dementia (PWD), the current paper offers an exploratory insight into the potential use of a structured singing group activity for beneficial outcome. The paper begins by outlining the relevance of music interventions for PWD and goes on to acknowledge that carers also need to be given tools to manage their own mood and stress levels. It continues by describing controlled practical work and its results in terms of quantitative and qualitative reports of the impact of group singing for PWD and their carers. The mixed methods approach enables the authors to gain some insights into ecologically-grounded work that by its very nature engages people in small groups.

\section{Why is music a potentially useful intervention for people living with dementia?}

Dementia, characterised by the development of multiple cognitive deficits that are caused by disorders affecting the brain, and its effects include memory impairment and at least one other cognitive disturbance, for instance aphasia or disruption in executive functioning (American Psychiatric Association, 2000). Several psychological problems have been associated with the dementia. For instance, while a study of elderly adults discovered that at follow-up, those with depressive symptoms were more likely to have dementia relative to those without such symptoms (Jorm, 2001), other research reported that the presentation of depressive symptoms coincided with or followed the onset of dementia, rather than preceding it (Butters et al., 2008; Korczyn and Halperin, 2009). Anxiety disorders are also frequently observed in individuals with dementia, with prevalence rates ranging between 17\% and 38\% (Ballard et al., 1996; Ballard et al., 2000; Ballard et al. 1994; Wands et al., 1990).

Musical involvement by PWD has demonstrated positive outcomes in psychological factors, such as the PWD's level of depression (Cooke et al. 2010a; Han et al., 2011), anxiety (Guetin et al., 2009; Sung et al., 2010), and agitation (Lin et al., 2011). An additional benefit specific to involvement in group music programs is the avenue for social interaction, which is often severely negatively impacted following the progression of a dementia.

A study by Lin et al. (2011) examined whether group music intervention reduced agitated behaviour in elderly PWD who reside in nursing facilities. They employed a randomised experimental paradigm where the experimental group $(N=49)$ received a total of twelve 30-minute group music intervention sessions (conducted twice weekly for six consecutive weeks) while the control group $(N=51)$ participated in normal daily activities. The level of aggression displayed by the PWD was assessed before the intervention, at the sixth and twelfth group sessions, and at one month following cessation of the intervention. The experimental group displayed improved performance (reductions in: agitated behaviour in general; physically non-aggressive behaviour; verbally non-aggressive behaviour; and physically aggressive behaviour) at the sixth and twelfth sessions, and at the one-month follow up. A reduction in verbally aggressive 
behaviour was only observed at the sixth session. Lin et al. (2011) concluded that group music intervention alleviated agitated behaviour in PWD; however they did not explore other benefits of such musical intervention, such as improvement in mood, lucidity, or focus.

Hammar et al. (2011) conducted a study that investigated expressions of emotions and resistance to care among PWD $(N=10)$ during morning care situations either with or without music therapeutic caregiving (MTC; this involves the caregiver singing either to or with the PWD during caregiving). When MTC was employed, a significant decrease in only three (i.e., pull away, grab object, and adduct) of the 13 resistant behaviours exhibited by the PWD was observed. Positively expressed emotions (i.e., pleasure and general alertness) by the PWD significantly increased under the MTC intervention, relative to the standard morning care sessions. However, they did not observe a significant decrease in any of the negatively expressed emotions (e.g., anger, anxiety, and sadness) examined. These results may be explained by the nature of the intervention, as MTC is primarily a receptive form of singing that involves the caregivers singing songs they chose based on what they preferred to sing, and there is no emphasis on the PWD participating in the activity. Hammar et al. (2011) concluded that MTC can be an effective intervention to provide PWD a more pleasant experience of morning care situations as it decreases resistant behaviour and increases positive emotions. This study was designed to improve the interpersonal relationship between PWD and their caregivers, with the goal of improving the morning care situation for the PWD. As such, the benefits to the PWD were emphasised, yet no direct benefit to the caregiver was highlighted.

\section{A need for work with persons living with dementia and their carers together}

As described above, a body of research has investigated the benefits of musical involvement for PWD, yet few studies have investigated the potential benefits for their coparticipating carers. In both community and residential care settings, it is often the case that the regular family carer or professional carer accompanies the PWD to a recreational or therapeutic activity deemed to be potentially beneficial to the PWD, with the potential impact of these activities on the carers themselves being largely overlooked. Indeed, relative to the amount of information available regarding PWD, substantially less knowledge exists for those who care for PWD (Australian Institute of Health and Welfare, 2007; Schofield et al. 1996).

An Australian national survey that collected data about carers (Survey of Disability, Ageing, and Carers; SDAC) found that $46 \%$ of caregivers reported at least one adverse effect that resulted from their caring role (Australian Institute of Health and Welfare, 2007). Adverse effects included frequently feeling resentful or angry about their caring role, being diagnosed with a stress-related illness, feeling weary or lacking energy, or feeling worried or depressed. The majority of Australian studies have reported a link between carer burden and the behavioural and psychological symptoms associated with dementia (Australian Institute of Health and Welfare, 2007). Therefore, as evidence supports improved behavioural and psychological outcomes for PWD following musical intervention, it is also valuable to determine whether such musical involvement positively impacts outcomes for caregivers. 


\section{Current study}

The work described in this paper comprised two stages: firstly, we created a singing group program for PWD and their caregivers. This program built on systematic earlier work in which an approach was developed suitable for seniors, structured for positive physical and psycho-social outcome (see Davidson and Faulkner, 2010). This comprised a warming session for voice and body, including diaphragmatic support and breathing exercises and some physical stretches; also, some musical games, for technical and social impact; and a broad selection of repertoire comprising both familiar and new. A socialising tea break was also included in the approach and the session lasted 2 hours.

In the current context, we wished to apply the principles of the structured singing group format to the PWD to examine whether any significant change in a PWD's lucidity, mood, agitated behaviour, and focus could be found ${ }^{\text {a }}$. In addition, we aimed to examine directly whether the caregivers' own energy, mood, level of stress/relaxation and focus was improved following attendance at the group singing session.

As a control activity, we also investigated whether any significant changes in these variables were observed in PWD following involvement in a quiz. The quiz drew from materials used by some of the occupational therapists involved with the PWD in the current project and represented a well-established tool for engagement for PWD. As an oral presentation, it included many of the same fun elements of presentation of questions, informal chat and entertainment involved in the singing activity (see Holthe et al., 2007; also Dowling, 1995).

In a second stage, we sought to determine whether any additional benefit in these PWD and caregiver variables was observed when attending six consecutive weekly singing sessions. Given the positive results of Lin et al's (2011) study after six weeks of group singing sessions, this was felt to be the minimum timeframe in which any on-going benefit may be detected. Though these were only once a week as opposed to twice a week as in Lin et al.'s study, our session lasted for 2 hours and were immersive experiences, so we hoped that the length of study would compensate for the lesser frequency. Also, most music therapy and community music activities tend to happen on a weekly basis, so we wanted to replicate this norm and also reflect the goal of the organisations supporting the activity, that is to hold weekly activities for members. If attendance at successive weekly group singing sessions demonstrates a residual benefit on these variables (i.e., an improvement in a variable post-session carries over to a higher baseline rating at the following week's pre-session rating), this would support promotion of continued attendance at group singing sessions for PWD and/or their caregivers.

It was evident from the start of the project that none of groups would reach sufficient membership to produce statistically robust data. For example, Group B was scheduled immediately after lunch, making it difficult to access one professional carer per PWD, and also given the relatively small size of the drop-in centre supporting Group A, it was impossible to recruit more than 12 people to this specific study. Nonetheless, it was felt that as an exploratory study it was worth exploring the small pool of data in quantitative terms, given the overarching prevalence of quantitative research model for investigations with these populations. Also, means scores can show an overarching trend in the data even when based on a small data set. To supplement these data, however, informal qualitative semi-structured interviews were also used to engage all participants in Stage 2, and as mentioned above, the facilitator was also asked to contribute her reflections. It is also 
to be noted that these cohorts are real groups, working in an on-going manner, therefore we believed it to be important to collect data reflective of actual practice and experience.

\section{Method}

\section{Ethics Statement}

The project was approved by The University of Western Australia's Human Research Ethics Committee (HREC) and written informed consent was obtained from all participants, following a protocol approved by the HREC that was also in accordance with the principles expressed in the Declaration of Helsinki. Capacity to provide informed consent was a criterion for inclusion in the study. Note that whilst the quantitative data reported in this paper were provided by the caregiver (i.e., they completed proxy reports for the PWD they cared for), brief qualitative interviews were carried out during Stage 2 of the study to attempt to offer richer insight into their singing group experience, and these included feedback from the PWD as well as the carers and the facilitator.

\section{Participants}

At Stage 1 the groups were led by a facilitator who had worked extensively with the principal author in developing the original singing program (reported by Davidson and Faulkner, 2010). It is to be noted that this person was not only an expert in singing, but had enjoyed a long career working with community and elderly groups in a variety of contexts, including the development of quizzes, story-telling and other activities. This meant that she undertook the singing and quiz activities with each of the study groups from an equal skill-base. Although she did not engage in the quantitative study herself, at Stage 2 she was interviewed and her qualitative insights are represented in this paper.

As the study attempted to achieve ecological validity, it worked with groups created for on-going purpose, and these were initiated by the facilitator at the request of two organisations. The membership of the two singing groups comprised participants who had received a diagnosis of dementia and their caregivers. Group A was made up of members of an Alzheimer charity that operated with a drop-in day centre. This singing group was a voluntary program organised for PWD living in the community. It involved six PWD and their caregivers who were family member, either partner or child (total $\mathrm{N}=12$ ). Group $\mathrm{B}$ was established at a residential care facility and contained PWD $(\mathrm{N}=11)$ and their professional caregivers based at the residential facility $(\mathrm{N}=4)$. All PWD were aged 70 years and over (range, mean, and standard deviation of the PWD's age were Group A: 73 - 88, 79.50, 5.75, and Group B: 65 - 97, 82.42, 8.90, respectively), and there was no significant difference in age between the two groups $\left(t_{(16)}=.725, p=.479\right)$. Each PWD was diagnosed by their medical doctor as having a either mild or moderate dementia as classified by the DSM-IV-TR (American Psychiatric Association, 2000). The range, mean, and standard deviation of the caregiver's age were Group A: 42-86; 69.67; 16.21, and, Group B: 44-63; 54.25; 8.18, respectively. No significant difference in caregiver age was observed between the two groups $\left(t_{(8)}=1.736, p=.121\right)$. For the quiz control activity, eight PWD participated (mean age and standard deviation were 86.88 and 5.28 respectively). No significant differences in PWD age were observed between the singing group and quiz groups $\left(t_{(24)}=1.76, p=.091\right)$. 


\section{Activities}

The singing activities were developed from earlier work with senior singers (Davidson and Faulkner, 2010), with specific items for delivery in the sessions being chosen by the facilitator. The Stage 1, a single singing session ran according to the principles outlined by Davidson and Faulkner (2010) and was undertaken to immerse the participants in the group singing experience. Given the membership included PWD, the session required considerable management to organise the PWD into the rehearsal room and have them settled. Therefore, the two hour time period was also chosen to avoid rushing in and out of the session and also to encourage informal chat and a tea break, all adding to the ambience of the experience. The quiz session took a similar format and engaged participants in similar ways. At Stage 2, a total of six $\times 2$-hour long sessions were delivered to Group A, building and progressing vocal warm-ups, main repertoire, musical games and tea break, in accordance with the facilitator's usual practice in applying the training method devised by Davidson and Faulkner.

\section{Assessment Materials}

Across the singing and quiz activities, assessment through bi-polar rating scales drew on behaviours commonly reported as difficulties experienced by PWD and their caregivers (American Psychiatric Association, 2000; Australian Institute of Health and Welfare, 2007; Ballard et al., 1996; Ballard et al., 2000; Cooke et al. 2010b; Finkel, 2003). For the PWD, two four-item scales were used: Confused - Lucid, Negative Mood - Positive Mood, Agitated - Relaxed, and Unfocused - Focused. Carers made proxy responses for the PWD using a five-point scale. Data were captured two hours prior to and two hours following the singing and quiz sessions. The caregivers also made their own self-assessments, indicating where they fitted on four bipolar five-point scales assessing: Tired - Energised, Negative Mood - Positive Mood, Stressed - Relaxed, Unfocussed - Focused.

In addition to these quantifiable measures, participants who took part in the six-week trial were questioned informally immediately after the sessions.

\section{Procedure}

Stage 1

The pre- and post-session scales (proxy and self-assessments) were distributed to the caregivers of singing and quiz group members prior to the session, and they were requested to record their responses based on ratings made two hours prior to the session and in the two hours following the session. For Group A, each PWD had their caregiver (a significant other) participate in the singing sessions and complete their proxy report, as is commonly practised in quantitative studies of PWD. However for Group B and the quiz group, as there were more PWD than there were caregivers, each caregiver reported on several PWD that they cared for.

\section{Stage 2}

Members of Group A undertook the quantitative questions and in addition, very short qualitative interviews were undertaken, in which simple questions were asked about feelings, mood and experience. Both PWD and carers were interviewed by the researchers, using a conversational approach. Note that from the individuals studied, there was no difficulty in obtaining verbal responses. Group A was selected for this second stage of the 
study owing to the fact that PWD-carer pairs were family members and that these people were in the closest relationships. Also, although the professional carers in Group B were keen to participate, they were very limited in their time available to offer extra input. Again owing to time demands on the participants in this second study, it was only possible to collect Stage 2 data fortnightly over the six-week trail (weeks 2, 4 and 6). Whilst these were inevitable compromises, they nonetheless reflected the real world environment facing facilitators working with these populations.

\section{Results}

Stage 1

The pre- and post-session measures were administered to the singing group participants and the data were analysed for each group separately, and with both groups' data combined. Paired samples t-tests were performed to determine whether any significant changes were observed pre- to post-singing session.

\section{Group $A$}

All $t$-values were negative, reflecting a trend of improvement in all variables from pre- to post-session, with PWD lucidity $\left(t_{(5)}=-2.666, p<.05\right)$ and caregiver $\operatorname{mood}\left(t_{(5)}=-3.162\right.$, $p<.05)$ being significantly improved.

\section{Group B}

Again, all $t$-values were negative, indicating a trend of improvement in variables following the singing session. PWD lucidity $\left(t_{(10)}=-3.614, p<.01\right)$, agitation $\left(t_{(10)}=-2.390, p<.05\right)$, and focus $\left(t_{(10)}=-3.464, p<.01\right)$ were significantly improved, with mood approaching significance $\left(t_{(10)}=-2.193, p=.053\right)$. None of the caregiver variables were significantly improved, however Energy was approaching significance $\left(t_{(3)}=-3.000, p=.058\right)$.

\section{Combined data from singing groups}

An improvement across all PWD variables was observed (lucidity: $t_{(16)}=-4.243, p<.01$; mood: $t_{(16)}=-2.781, p<.05$; relaxation: $t_{(16)}=-2.781, p<.05$; and focus: $t_{(16)}=-3.816$, $p<.01)$. Furthermore, by combining data across groups, three of the four caregiver variables were also significantly improved (energy: $t_{(9)}=-3.000, p<.05$; mood: $t_{(9)}=-3.000$, $p<.05$; focus: $\left.t_{(9)}=-2.449, p<.05\right)$ ), with the fourth variable 'relaxation' approaching significance $\left(t_{(9)}=-2.236, p=.052\right)$.

Paired samples t-tests for the control pre- and post-quiz data revealed no significant changes in the four PWD variables (lucidity: $t_{(7)}=0.00, p=1.00$; mood: $t_{(7)}=-.552$, $p=.598$; relaxation: $t_{(7)}=-.552, p=.598$; and focus: $\left.t_{(7)}=0.00, p=1.00\right)$.

Given these results, it was decided at Stage 2 that it would not be necessary to run a control group, especially in the context of work which revealed PWD tend to retain a responsiveness to music, rather than verbal communication (Simmons-Stern et al. 2010).

\section{Stage 2}

Data were additionally collected fortnightly from Group A across a six-week period. Unfortunately, but typical of the cohorts studied, at week 4, two PWD and their two Caregivers were unable to attend, and in week 6, two PWD and one caregiver were unable to attend. Thus, the quantitative data were extremely weak, so when examining for any pre- and post-session differences at weeks 2,4 , and 6 , significant differences were only observed in the PWD's level of focus in Week $2(t(5)=-3.162, \mathrm{p}<.05)$ where attendance 
was highest, and reflecting an improvement in their focus post-singing group session. The lack of significant differences in the other variables and weeks in this extra data collection is very likely due to the limited power of the study, as significant differences were observed across all variables (with the exception of caregiver relaxation) when the data collected from the singing groups was combined and so the $\mathrm{N}$ met a good minimum standard $(\mathrm{N}=25)$ (as reported above). The pre- and post-session trends reflected an improvement in all variables (with the exception of caregiver focus in Weeks 2 and 4).

To determine whether there was any additional benefit from attending consecutive singing sessions over the six-week period, the pre- and post- scores that were calculated for each variable (for the PWD and for their caregiver, at 2, 4, and 6 weeks) were normalised. These data were then fitted with a linear regression, to determine whether the slope of the linear function was significantly different than zero, reflecting an additional benefit of regular attendance at the singing group sessions. All slopes were positive, reflecting a trend of improvement in the variables from session to session. A significant benefit from attending consecutive sessions was observed in three of the four PWD variables (lucidity: $(\mathrm{F}(1,4)=13.700, \mathrm{p}<.05)$; $\operatorname{mood}(\mathrm{F}(1,4)=9.600, \mathrm{p}<.05)$; focus: $(\mathrm{F}(1,4)=$ 42.42, $\mathrm{P}<.01)$; relaxation: $(\mathrm{F}(1,4)=3.321, \mathrm{p}=.143))$. For the caregiver, such additional benefit in attending consecutive singing group sessions was observed in their level of relaxation (relaxation: $\mathrm{F}(1,4)=8.955, \mathrm{p}<.05)$ ), however no significant effect was observed in the other variables (energy: $(F(1,4)=2.048, p=.226)$; $\operatorname{mood}(F(1,4)=2.001$, $\mathrm{p}=.230)$; and focus $(\mathrm{F}(1,4)=.034, \mathrm{p}=.86)$.

The qualitative interviews with the PWD and their caregiver, though collected in brief interactions, complimented the main rating scales. Researcher-led discussion took place with the PWD and his/her carer, and through these interactions it became obvious to the researchers that the carers not only had great insight into the moods and behaviours of the PWD, but that they were extremely sensitive to the impact of the singing groups over time, on both parties. Indicative positive comments collected on different occasions are captured in in Table 1 below. Table 2 highlights some negative comments and Table 3 shows other factors of significance to the participants to have emerged in the brief interviews.

Together these qualitative data reveal that when given the opportunity to comment, the majority of participants believed the variables under investigation to be important and positively reinforced in the singing group context. Where negative comments are made, it is evident that the PWD or the carer has displayed a lower mood behaviour that was perhaps not so effectively regulated by the singing that day, though these were only small negative reflections set within a positive overall experience. Finally, some other emergent factors are worthy of further comment: the potential for positive identity construction that seemed to be elicited by the activity of singing, which in turn appeared to facilitate socio-emotional connection between carer and PWD. This effect was also reflected in the specific value of reminiscence. More generally, the physical proximity afforded by group singing also seemed to offer participants a type of closeness that might have otherwise been changed or lost through the effects of the dementia.

Taking the data shown in these three tables together, it can be seen that participants overwhelmingly perceived positive value in the vocal activity, with the core factors of 


\begin{tabular}{|c|c|c|c|}
\hline $\begin{array}{l}\text { Person making } \\
\text { comment }\end{array}$ & $\begin{array}{l}\text { Week } \\
\text { comment } \\
\text { made }\end{array}$ & $\begin{array}{l}\text { Target } \\
\text { behaviour }\end{array}$ & Comment \\
\hline Proxy for PWD 1 & 4 & Lucidity & 'He is really attentive in rehearsal.' \\
\hline Carer 1 & 6 & & $\begin{array}{l}\text { 'Looking across these sessions, I've noticed us [PWD and } \\
\text { themselves] both being more clear, and even more rational } \\
\text { after the sessions. That is a big difference and l'd say the } \\
\text { impact of working over the weeks.' }\end{array}$ \\
\hline Facilitator & 2 & & $\begin{array}{l}\text { 'Beautiful to see some members emerge from a fog of } \\
\text { confusion as the sessions unwind. That one particular } \\
\text { lady, well, she was totally clear by the end of the session.' }\end{array}$ \\
\hline PWD 4 & 2 & Energy & 'I feel ready to dance and sing!' \\
\hline Carer 4 & 4 & & $\begin{array}{l}\text { 'She seems to have a lot more bounce after the sessions, } \\
\text { chattering and singing away.' }\end{array}$ \\
\hline Carer 3 & 6 & & $\begin{array}{l}\text { I'm astonished how these sessions have touched me. I can't } \\
\text { really explain why, but I feel much more energetic after } \\
\text { singing, which is good, as we often have lunch before } \\
\text { coming along so I would normally feel like a snooze.' }\end{array}$ \\
\hline Proxy for PWD 6 & 2 & Focus & $\begin{array}{l}\text { 'All I can say is that he was alert and responsive throughout. } \\
\text { Not that usual these days!' }\end{array}$ \\
\hline PWD 1 & 4 & & 'I'm ready as I understand music.' \\
\hline Carer 5 & 6 & & $\begin{array}{l}\text { 'Yes, singing lets me focus. I just concentrate on what l've } \\
\text { got to do. It is a time when I can let everything else go } \\
\text { from my mind.' }\end{array}$ \\
\hline PWD 2 & 6 & Mood & $\begin{array}{l}\text { 'I feel pretty, oh so pretty and gay! [quoting words from a } \\
\text { song in the musical West Side Story, and laughing] }\end{array}$ \\
\hline Carer 2 & 6 & & $\begin{array}{l}\text { 'It's marvellous to see him happy, and it lifts my spirits too. Each } \\
\text { week it seems to get better. We both look forward to coming.' }\end{array}$ \\
\hline Facilitator & 4 & & $\begin{array}{l}\text { 'As time passes and you get to know people more, you can see } \\
\text { the singing shaping their mood. Someone comes in grumpy } \\
\text { and leaves happy and smiling. I work to achieve those sort of } \\
\text { outcomes.' }\end{array}$ \\
\hline Carer 6 & 4 & Relaxation & $\begin{array}{l}\text { 'Singing is a 'chill pill'. I couldn't believe my luck when I saw the } \\
\text { group advertised. It's been so lovely. It is really tough caring for } \\
\text { Dad, but coming here and singing, well it just washes all my } \\
\text { troubles away. I feel so calm afterwards. I reckon that I need it } \\
\text { much more than he does.' }\end{array}$ \\
\hline Facilitator & 6 & & $\begin{array}{l}\text { 'I'm usually worn out by the end of a session as there is a lot to } \\
\text { manage. But, I also know that the singing itself gives me a sort } \\
\text { of balance and certainly calming effect. Look at these people } \\
\text { over this course of singing work, they are ALL much more } \\
\text { relaxed than when they first came here six weeks ago.' }\end{array}$ \\
\hline
\end{tabular}

These represent the overarching content of some $72 \%$ of the responses made.

lucidity, focus, energy, mood and relaxation all being present and indeed - even within the small cohort studied - developing as engagement increased over the sessions.

\section{Discussion}

This study was made possible by creating two singing groups containing PWD and their caregivers. The aim was to determine whether attendance at a one off or more extended weekly two hour singing sessions had positive impact for the group members. When analysing the combined data from the two singing groups, though quantitatively small, the data nonetheless produced positive analyses, revealing encouraging changes in the PWD's 
Table 2 Negative target behaviour comments offered across the six week program by carers, PWD and the facilitator

\begin{tabular}{|c|c|c|c|}
\hline $\begin{array}{l}\text { Person making } \\
\text { comment }\end{array}$ & $\begin{array}{l}\text { Week } \\
\text { comment } \\
\text { made }\end{array}$ & $\begin{array}{l}\text { Target } \\
\text { behaviour }\end{array}$ & Comment \\
\hline Proxy for PWD 2 & 2 & Lucidity & $\begin{array}{l}\text { 'She has been confused for most of the session. Not sure } \\
\text { she really understands what's going on today.' }\end{array}$ \\
\hline Carer 4 & 2 & $\begin{array}{l}\text { Energy- into } \\
\text { Mood }\end{array}$ & $\begin{array}{l}\text { 'I don't know, he seems full of life, but I feel a bit lack-lustre. } \\
\text { It could be my mood. I'll snap out of it. Nothing too serious.' }\end{array}$ \\
\hline Carer 1 & 4 & $\begin{array}{l}\text { Mood- into } \\
\text { Relaxation }\end{array}$ & $\begin{array}{l}\text { I'm not so relaxed today. Erm, I am and I'm not. I'm relaxed } \\
\text { as I have the time to enjoy myself, but I feel tense as he's not } \\
\text { doing so well. I'm worrying about that, but he seems to be } \\
\text { have had a grand old time.' }\end{array}$ \\
\hline
\end{tabular}

Note that these represent no more than $12 \%$ of the total data collected.

lucidity, mood, agitation, and focus, observed from the two hours prior to a one-off singing session to the two hours post-session. Such positive changes were not observed in these variables following involvement in the control activity of a quiz. Further, caregivers' energy levels, mood, and focus were improved from pre- to post-singing group session (and their mean level of relaxation had also increased and was approaching significance). In addition, attendance at the Group A sessions over six weeks had positive effects on the PWD's baseline level of lucidity, mood, and focus when assessed in the following fortnight's session. Similarly, attending consecutive weekly singing sessions had positive impacts on the caregivers' stress level, with an increase in their baseline level of relaxation occurring from session to session. The residual benefit of these variables, which was observed fortnightly over the six-week period, supports the promotion of regular attendance at singing sessions for PWD and their caregivers. Further to these small-scale quantitative outcomes, the qualitative reports generally support these data, offering a richer and human face to the rating scale results.

Table 3 Additional comments offered across the six-week program by carers, PWD and the facilitator relating to matters considered to be of importance, but not related to the target behaviours

\begin{tabular}{|c|c|c|c|}
\hline $\begin{array}{l}\text { Person } \\
\text { making } \\
\text { comment }\end{array}$ & $\begin{array}{l}\text { Week } \\
\text { comment } \\
\text { made }\end{array}$ & $\begin{array}{l}\text { Theme } \\
\text { introduced }\end{array}$ & Comment \\
\hline Carer 5 & 6 & $\begin{array}{l}\text { Positive identity } \\
\text { construction }\end{array}$ & $\begin{array}{l}\text { 'The thing I've noticed about this experience is how it shows } \\
\text { him in a good light. I often look at him and think "that's not } \\
\text { the man I married". But then since I've been hearing him } \\
\text { singing and looking and behaving like a normal man and I } \\
\text { think "that's him, he's still my husband in there."' }\end{array}$ \\
\hline Facilitator & 6 & $\begin{array}{l}\text { Positive memories/ } \\
\text { reminiscence }\end{array}$ & $\begin{array}{l}\text { The work stimulates memories- the reminiscence of how } \\
\text { the person was, but also how the person with dementia can } \\
\text { remember things. It is often quite moving to experience the } \\
\text { impact of that memory light bulb switching on.' }\end{array}$ \\
\hline Carer 2 & 6 & $\begin{array}{l}\text { Socio-emotional } \\
\text { connection }\end{array}$ & $\begin{array}{l}\text { It is remarkable, the singing has been remembered from } \\
\text { week to week and today we were really eager to get here. } \\
\text { I'm so pleased the group is continuing. You can make } \\
\text { friends through this sort of group. }\end{array}$ \\
\hline PWD 3 & 4 & Proximity & 'Nice having everyone so close and around you.' \\
\hline Carer 3 & 6 & & $\begin{array}{l}\text { 'We both enjoy the closeness. It is good to feel the others } \\
\text { huddled around, swaying with you in the music.' }\end{array}$ \\
\hline
\end{tabular}


This study is novel in that it demonstrates the potential benefit available to elderly PWD and their caregivers following attendance at a weekly singing group. Until now, no study has directly explored whether such improvements experienced by PWD following musical intervention can similarly be observed in caregivers if musical involvement is also undertaken. This is surprising given the impact the role of 'caregiver' has on those who undertake such a role to care for PWD. As mentioned in the introduction to this paper, a report produced by the Australian Institute for Health and Welfare (AIHW) following a national data analysis of dementia in Australia, noted that $46 \%$ of caregivers reported at least one adverse effect as a result of their caring duties (2007). These adverse effects included frequently feeling anger or resentment about their caring role, being diagnosed with a stress-related illness, feeling weary or lacking energy, or frequently feeling anxious or depressed because of the caring role. Further the AIHW report (2007) noted that most Australian studies report a link between carer burden and the behavioural and psychological symptoms associated with dementia. More than half (61\%) of co-resident primary carers (similar to the Group A caregivers employed in this study) reported that the caring role had at least one adverse main effect on their relationships with other family members and friends, thus affecting their level of social interaction (Australian Institute of Health and Welfare, 2007). Therefore, involvement in a singing group results not only in the improvements reported in this study (i.e., improvement in energy levels, mood, and level of focus) but provides these workers with a context for social interaction, both with other caregivers, and with the individuals they care for.

This preliminary study investigated the impact of singing group involvement on various caregiver and PWD variables, both immediately following a singing session, and also across a number of consecutive weekly singing sessions. As the number of participants in the study was low, this led to difficulties in establishing significant results. Preand post-session data were collected from both groups and combined to increase the power of the study. This was chosen to be the preferred method, given that large groups of singers are not typical for this form of intervention. The qualitative data offer positive triangulation for the quantitative data, suggesting that whilst exploratory, the study has offered novel and useful insights into the value of singing with PWD and their carers. Of course, we were dependant on volunteers, who may have been positively focused towards singing and ideally further study is necessary to validate all of these outcomes. However, in terms of ecological validity, community and residential care relies on volunteer participation from its membership, so finding activities that are attractive to them is of course necessary.

In effect, this study raises the on-going challenge for investigations of PWD, that is the difficulty in recruiting sufficiently large enough samples for meaningful investigation. The triangulation of research methods in the current work produced a detailed set of results, but, the recruitment situation explains why there is a paucity of research in this particular area.

This study promotes the idea of using singing for improving the abovementioned outcomes for PWD, and also for their caregivers. Further, regular singing group attendance is recommended for PWD and their caregivers, as it was observed that there is additional benefit gained from attending consecutive singing group sessions. 


\section{Endnote}

${ }^{a}$ Note that some of the raw data drawn upon in this study have been used in other analyses. The current paper focuses specifically on carers and PWD and looks at the material in a completely unique manner, relative to the aim of the study, and as such is analysed as 'new' data.

\section{Competing interests}

The authors declare that they have no competing interests.

\section{Authors' contributions}

The authors' contributions to the paper are equal. The overall project conception, some of the literature surveyed and the qualitative data analysis are the work of the first author. The specific study design, some literature and all of the quantitative analyses were undertaken by the second author. Both authors read and approved the final manuscript.

\section{Author details}

${ }^{1}$ Faculty of the Victoria College of the Arts and the Melbourne Conservatorium of Music, The University of Melbourne, Building 141, Royal Parade, Parkville VIC 3010, Australia. ${ }^{2}$ School of Psychology, The University of Western Australia, 35 Stirling Hwy, Crawley, WA 6009, Australia.

Received: 24 April 2014 Accepted: 27 October 2014

Published online: 18 December 2014

\section{References}

ADI, World Alzheimer Report. (2010). The Global Economic Impact of Dementia (p. 2010). London: Alzheimer's Disease International.

American Psychiatric Association. (2000). Diagnostic and Statistical Manual of Mental Disorders, Fourth Edition, Text Revision (DSM-IV-TR). Washington, DC: American Psychiatric Association.

Australian Institute of Health and Welfare. (2007). Dementia in Australia: National data analysis and development. Canberra: AlHW.

Ballard, C, Boyle, AN, Bowler, C, \& Lindesay, J. (1996). Anxiety disorders in dementia sufferers. International Journal of Geriatric Psychiatry, 11(11), 987-990

Ballard, C, Neill, D, O'Brien, J, McKeith, IG, Ince, P, \& Perry, R. (2000). Anxiety, depression and psychosis in vascular dementia: prevalence and associations. Journal of Affective Disorders, 59(2), 97-106.

Ballard, CG, Mohan, RNC, Patel, A, \& Graham, C. (1994). Anxiety disorder in dementia. Irish Journal of Psychological Medicine, 11(3), 108-109.

Butters, MA, Young, JB, Lopez, O, Aizenstein, HJ, Mulsant, BH, Reynolds, CF, DeKosky, ST, \& Becker, JT. (2008). Pathways linking late-life depression to persistent cognitive impairment and dementia. Dialogues in Clinical Neuroscience, 10(3), 345-357.

Cooke, M, Moyle, W, Shum, D, Harrison, SD, \& Murfield, J. (2010a). A randomized controlled trial exploring the effect of music on quality of life and depression in older people with dementia. Journal of Health Psychology, 15(5), 765-776.

Cooke, ML, Moyle, W, Shum, DHK, Harrison, SD, \& Murfield, JE. (2010b). A randomized controlled trial exploring the effect of music on agitated behaviours and anxiety in older people with dementia. Aging and Mental Health, 14(8), 905-916.

Davidson, JW, \& Faulkner, R. (2010). Meeting in music: The role of singing to harmonise carer and cared for. Arts and Health: An International Journal for Research, Policy and Practice, 2(2), 164-170.

Dowling, JR. (1995). Keeping Busy: A Handbook of Activities for Persons with Dementia. Baltimore: The Johns Hopkins University Press.

Finkel, SI. (2003). Behavioral and psychologic symptoms of dementia. Clinics in Geriatric Medicine, 19(4), $799-824$.

Guetin, S, Portet, F, Picot, MC, Pommie, C, Messaoudi, M, Djabelkir, L, Olsen, AL, Cano, MM, Lecourt, E, \& Touchon, J. (2009). Effect of Music Therapy on Anxiety and Depression in Patients with Alzheimer's Type Dementia: Randomised, Controlled Study. Dementia and Geriatric Cognitive Disorders, 28(1), 36-46.

Hammar, LM, Emami, A, Engstrom, G, \& Gotell, E. (2011). Communicating through caregiver singing during morning care situations in dementia care. Scandinavian Journal of Caring Sciences, 25(1), 160-168.

Han, PM, Kwan, M, Chen, D, Yusoff, SZ, Chionh, HL, Goh, J, \& Yap, P. (2011). A Controlled Naturalistic Study on a Weekly Music Therapy and Activity Program on Disruptive and Depressive Behaviors in Dementia. Dementia and Geriatric Cognitive Disorders, 30(6), 540-546.

Holthe, T, Thorsen, K, \& Josephsson, S. (2007). Occupational patterns of people with dementia in residential care: An ethnographic study. Scandinavian Journal of Occupational Therapy, 14(2), 96-107.

Jorm, AF. (2001). History of depression as a risk factor for dementia: an updated review. Australian and New Zealand Journal of Psychiatry, 35(6), 776-781.

Korczyn, AD, \& Halperin, I. (2009). Depression and dementia. Journal of the Neurological Sciences, 283(1-2), 139-142.

Lin, Y, Chu, H, Yang, CY, Chen, CH, Chen, SG, Chang, HJ, Hsieh, CJ, \& Chou, KR. (2011). Effectiveness of group music intervention against agitated behavior in elderly persons with dementia. International Journal of Geriatric Psychiatry, 26(7), 670-678.

Schofield, H, Bozic, S, Hermann, H, \& Singh, B. (1996). Family carers: Some impediments to effective policy and service development. Australian Journal of Social Issues, 31(2), 157-172. 
Simmons-Stern, NR, Budson, AE, \& Ally, BA. (2010). Music as a memory enhancer in patients with alzheimer's disease'. Neuropsychologia, 48(10), 3164-7.

Sung, HC, Chang, AM, \& Lee, WL. (2010). A preferred music listening intervention to reduce anxiety in older adults with dementia in nursing homes. Journal of Clinical Nursing, 19(7-8), 1056-1064.

Wands, K, Merskey, H, Hachinski, VC, Fisman, M, Fox, H, \& Boniferro, M. (1990). A questionnaire investigation of anxiety and depression in early dementia. Journal of the American Geriatrics Society, 38(5), 535-538.

doi:10.1186/s13612-014-0024-5

Cite this article as: Davidson and Almeida: An exploratory study of the impact of group singing activities on lucidity, energy, focus, mood and relaxation for persons with dementia and their caregivers. Psychology of Well-Being: Theory, Research and Practice 2014 4:24.

\section{Submit your manuscript to a SpringerOpen ${ }^{\circ}$ journal and benefit from:}

- Convenient online submission

- Rigorous peer review

- Immediate publication on acceptance

- Open access: articles freely available online

- High visibility within the field

- Retaining the copyright to your article

Submit your next manuscript at $>$ springeropen.com 